\title{
THE EFFECTS OF MORPHINE AND HALOTHANE ANAESTHESIA ON URINE NOREPINEPHRINE DURING SURGERY FOR CONGENITAL HEART DISEASE
}

\author{
Theodore H. Stanley, Wen-Shin Liu, † and George D. Lathrop:
}

LARGE DOSES of morphine $(0.5-1.0 \mathrm{mg} / \mathrm{kg})$ produce cardiac inotropic enhancement which is catecholamine dependent in mongrel dogs. ${ }^{1}$ In a recent report we showed that anaesthetic doses of morphine $(3 \mathrm{mg} / \mathrm{kg}$ ) cause elevated urine norepinephrine levels in patients undergoing coronary artery grafting procedures but only during and after bypass and postoperatively. ${ }^{2}$ Subsequently we found that patients with mitral and aortic valve disease had a different response to morphine anaesthesia. ${ }^{3}$ These patients experienced an immediate increase in urine norepinephrine during induction of anaesthesia, which was maintained throughout the operative procedure and post-operatively and resulted in norepinephrine excretion rates that were significantly higher than in our patients with coronary artery disease. The differences in results of the studies suggested that preoperative disease can alter catecholamine responses to morphine anaesthesia. This study was conducted to determine and to compare urine norepinephrine concentrations and excretion rates in patients with cyanotic and noncyanotic congenital heart disease before anaesthesia, after induction with morphine or halothane anaesthesia and during and after surgical correction of the cardiac lesions.

\section{Methods}

A total of 40 children 6 to 11 years old who were undergoing complete correction of atrial septum defect of the secundum type (ASD) or Tetralogy of Fallot (TF) served as the subjects for the investigation. Each patient was randomly assigned preoperatively to receive halothane or morphine anaesthesia. There were thus four groups of patients. Groups ASD I and TF I were given morphine and groups ASD II and TF II were given halothane. Seven of the $15 \mathrm{TF}$ patients had had a previous subclavian to pulmonary artery anastomosis done. The remainder had never been operated on before. None of the 25 patients undergoing ASD repair had had previous cardiac operations.

Premedication consisted of pentobarbitone $1 \mathrm{mg} / \mathrm{kg}$ body weight, morphine 1 $\mathrm{mg} / 10 \mathrm{~kg}$ and atropine $0.05 \mathrm{mg} / 10 \mathrm{~kg}$ given 90 minutes prior to the operation. A

-Associate Professor of Anesthesiology.

tFellow in Anesthesiology.

tChief, Epidemiology Division, Brooks Air Force Base, San Antonio, Texas.

From the ${ }^{\circ}+$ Department of Anesthesiology, The University of Utah College of Medicine, Salt Lake City, Utah 84132 and the $\$$ Epidemiology Division, Brooks Air Force Base, San Antonio, Texas 78235 .

Presented at the Canadian Anaesthetists' Society meeting in Kingston, Ontario, June, 1975. 
bladder catheter was inserted at the time of premedication and urine was collected from then until anaesthesia was begun (first study period). Urine was also collected during the period from the beginning of anaesthesia until the incision ( second study period), from the incision until the start of cardiopulmonary bypass (third study period), during bypass (fourth study period) from end of bypass until the end of the operation (fifth study period) and during the first two postoperative hours (sixth study period). Urine specimens were collected in ambercoloured glass containers with sufficient $0.1 \mathrm{~N}$ hydrochloric acid added to maintain the $\mathrm{pH}$ between 2 and 3 . Each specimen was frozen until time of analysis. Collected urine was analyzed for norepinephrine by the automated fluorometric method of Viktora, Baukal and Wolff. ${ }^{4}$

Before anaesthesia was begun, two intravenous lines were started in the upper extremities; a central venous pressure catheter was placed either into the basilic vein in the antecubital fossa or into the internal jugular vein in the neck and threaded to the right atrium and a radial or brachial artery catheter was introduced. Systolic, diastolic and mean arterial blood pressures were recorded every five minutes during induction, during the entire operative procedure and for the first two hours post-operatively. Standard electrocardiographic leads were applied to the extremities. All patients received oxygen to breathe while morphine sulfate was given intravenously at a rate of $5-15 \mathrm{mg} / \mathrm{min}$ or halothane $0.5-1.5$ per cent was slowly added to the oxygen. Respirations were first assisted and then controlled in order to keep arterial $\mathrm{P}_{\mathrm{CO}_{2}}$ between 34-40 torr. Arterial blood samples for blood gas analysis were obtained every 15 minutes. When the patient became unresponsive, or a maximum of $4 \mathrm{mg} / \mathrm{kg}$ of morphine had been administered, succinylcholine $1.5 \mathrm{mg} / \mathrm{kg}$ body weight was given intravenously and the trachea was intubated. Controlled ventilation was continued. When succinylcholine paralysis disappeared, the patient was given d-tubocurarine $0.5-0.75 \mathrm{mg} / \mathrm{kg}$ over a period of 20 minutes and the operation was started. If additional anaesthesia was considered necessary during the operation, patients in the morphine groups received $2-5 \mathrm{mg}$ supplements of morphine and those in the halothane groups a higher concentration of halothane. During cardiopulmonary bypass $0-0.5$ per cent halothane was passed through the oxygenator in patients receiving halothane while those getting morphine received no supplemental medication.

Lactated Ringer's solution with 5 per cent dextrose was administered at a rate of $10-15 \mathrm{ml} / \mathrm{kg} / \mathrm{hr}$ during induction of anaesthesia and $1-2 \mathrm{ml} / \mathrm{kg} / \mathrm{hr}$ during the operation. Post-operatively, Ringer's lactate solution was administered at $1-3 \mathrm{ml} /$ $\mathrm{kg} / \mathrm{hr}$. Whole blood was the only colloid given routinely during operation and in the first two post-operative hours. During bypass, blood was added to the oxygenator as required to maintain a blood flow of at least $60 \mathrm{ml} / \mathrm{kg} / \mathrm{min}$. After bypass and in the recovery room, blood was given to maintain pre-operative central venous or intraoperative left atrial pressures.

The extracorporeal system consisting of Bentley oxygenator and Sarns roller pump was primed with $18-24 \mathrm{ml} / \mathrm{kg}$ of fresh heparinized whole blood and $30-40$

'Urine epinephrine was not measured because reagents necessary for the analysis were not available. 
TABLE I

PREOPERATIVE Data (MEAN \pm S.D.)

\begin{tabular}{|c|c|c|c|c|}
\hline & Anaesthetic & $\begin{array}{l}\text { Number of } \\
\text { patients }\end{array}$ & $\begin{array}{c}\text { Age } \\
\text { (years) }\end{array}$ & $\underset{(\mathrm{kg})}{\text { Weight }}$ \\
\hline Group ASD I & Morphine & 10 & $\begin{array}{c}8 \\
\pm 2.3\end{array}$ & $\begin{aligned} & 38 \\
\pm & 5\end{aligned}$ \\
\hline Group ASD II & Halothane & $1: i$ & $\begin{array}{c}9 \\
\pm 2.2\end{array}$ & $\begin{array}{l}39 \\
\pm 4\end{array}$ \\
\hline Group TF I & Morphine & $s$ & $\begin{array}{r}9 \\
\pm 1.6\end{array}$ & $\begin{aligned} & 27^{*} \\
\pm & 4\end{aligned}$ \\
\hline Group TF II & Halothane & 7 & $\begin{aligned} & 10 \\
\pm & 1.9\end{aligned}$ & $\begin{aligned} & 29^{*} \\
\pm & 3\end{aligned}$ \\
\hline
\end{tabular}

*P $<0.0 .7$, Student's t-test when compared to Group ASD I or Group ASD II.

$\mathrm{ml} / \mathrm{kg}$ of lactated Ringer's solution. Samples of mixed venous blood were obtained at the venous inflow to the oxygenator every 15 minutes and analyzed on a Radiometer acid-base analyzer for $\mathrm{P}_{\mathrm{O}_{2}}, \mathrm{P}_{\mathrm{CO}_{2}}$ and $\mathrm{pH}$. Bypass flows were maintained between $60-100 \mathrm{ml} / \mathrm{kg} / \mathrm{min}$ in order to keep the mixed venous oxygen tension between 38 and 42 torr. Mean blood pressure and extracorporeal flow rate were recorded every 15 minutes during bypass. Oesophageal temperature was monitored during operation with a Yellow Springs temperature probe. Patients were cooled to $32^{\circ} \mathrm{C}$ during bypass and rewarmed to $37^{\circ} \mathrm{C}$ at its conclusion. Temperature corrections were made for blood gas analysis of specimens obtained during hypothermia, using standard normograms. At the conclusion of bypass, calcium chloride was given routinely, the dose varying from 100 to $600 \mathrm{mg}$. No other inotropic agents were needed during the operative period. Post-operatively all patients were given 100 per cent oxygen and ventilation was controlled for at least two hours. During this period inotropic and analgesic drugs were not required.

\section{Results}

Eight of the 15 children with TF received morphine (group TF I) and seven were given halothane (group TF II). Ten patients with ASD received morphine (group ASD I) and 15 halothane (Group ASD II). The mean age of all four groups was similar ( Table I). However, both ASD groups were significantly heavier ( $\mathrm{P}<$ 0.05 ) than either of the two groups of TF patients.

Children with TF had significantly higher pre-operative (study period I) urine norepinephrine excretion rates than children with ASD $(\mathrm{P}<0.05)$ (Tables II and III). TF patients also had greater pre-operative urine outputs than ASD patients but this difference was not significant $(P>0.10)$. Patients in group TF I received an average of $76 \mathrm{mg}(2.8 \pm 0.4 \mathrm{mg} / \mathrm{kg})$ of morphine and those in group ASD I, $129 \mathrm{mg}(3.4 \pm 0.5 \mathrm{mg} / \mathrm{kg})$. Groups TF I and TF II had similar arterial blood pressures during all study periods. Group ASD I had similar arterial blood pressures as group ASD II during study periods I, II, V and VI but significantly higher pressures during periods III and IV (before and during bypass (Table IV). ASD I patients also had significantly higher blood pressures than TF I and TF II patients 
STANLEY, et al.: NOREPINEPHRINE EXCRETION






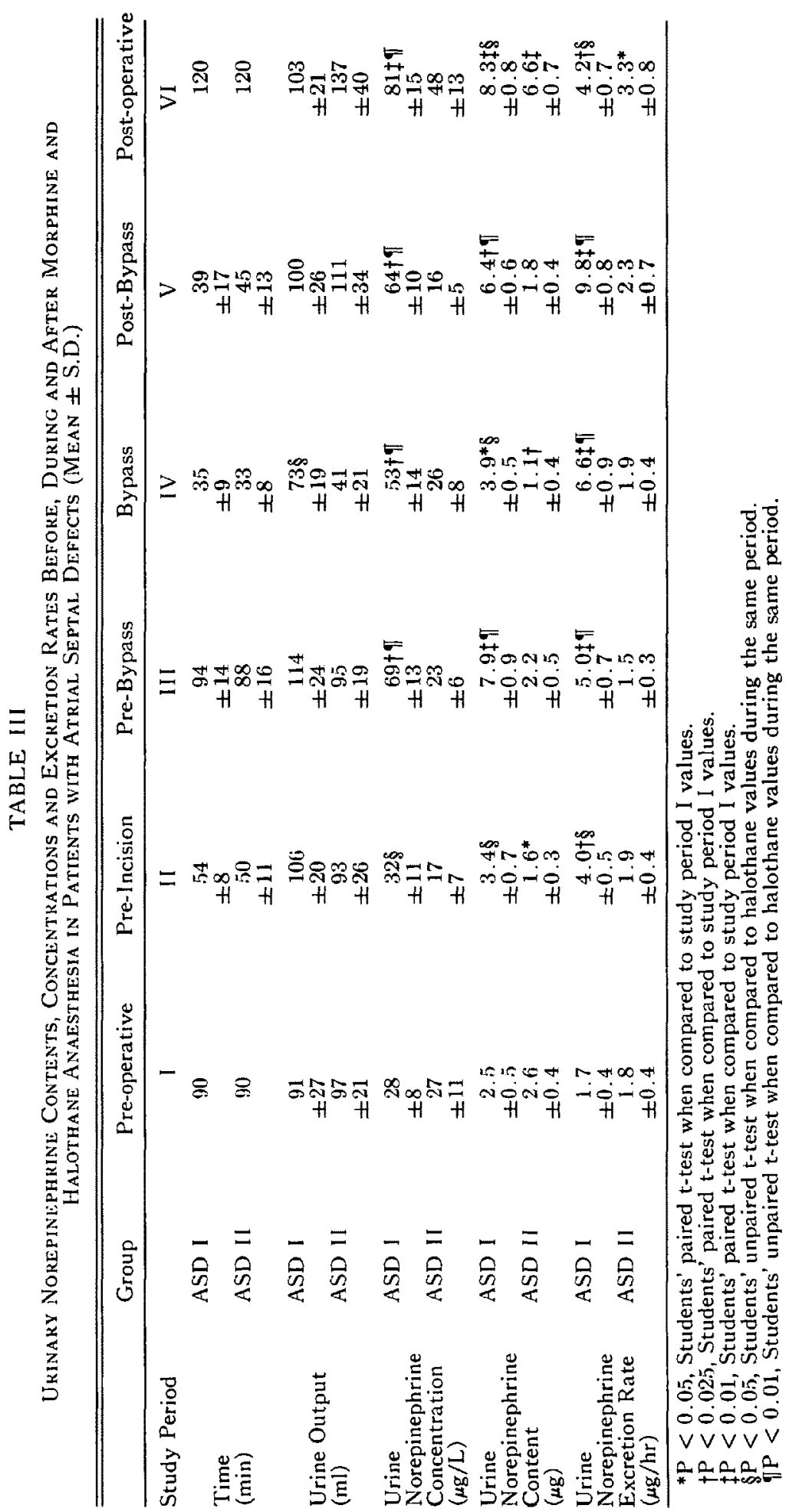


TABI.E IV

Mean Arterial Blood Pressure (Averacie \pm S. U.)

\begin{tabular}{lccccrr}
\hline \hline Study Period & I & II & III & IV & V & VI \\
\hline Groups & & & & & & \\
ASD I & 85 & 87 & 94 & 75 & 89 & 84 \\
& \pm 13 & \pm 9 & \pm 11 & \pm 8 & \pm 16 & \pm 11 \\
ASD II & 87 & 84 & $76^{*}$ & $48^{*}$ & 81 & 88 \\
& \pm 12 & \pm 7 & \pm 8 & \pm 7 & $\pm 1: 3$ & \pm 14 \\
TF I & 79 & 78 & $72^{*}$ & $59^{*}$ & 80 & 84 \\
& \pm 9 & \pm 10 & \pm 13 & \pm 11 & \pm 15 & \pm 13 \\
TF II & 80 & 74 & $68^{*}$ & $5 i^{*}$ & 79 & 86 \\
& \pm 14 & \pm 9 & \pm 14 & \pm 14 & \pm 9 & \pm 10 \\
\hline
\end{tabular}

'P $<0.05$, Students' t-test when compared to ASD I values during the same period.

TABI.E $V$

INTKaOpekative Data (Mrans \pm S.D.)

\begin{tabular}{|c|c|c|c|c|c|}
\hline \multirow[b]{2}{*}{ Group } & \multirow[b]{2}{*}{ Anaesthetic } & \multirow[b]{2}{*}{$\begin{array}{l}\text { length of } \\
\text { procedure (hr) }\end{array}$} & \multirow[b]{2}{*}{$\begin{array}{l}\text { Time } \\
\text { (niin) }\end{array}$} & \multirow{2}{*}{$\frac{\text { Bypass }}{\text { Mean arterial }}$} & \multirow[b]{2}{*}{$\begin{array}{c}\text { Flow } \\
(\mathrm{ml} / \mathrm{kg})\end{array}$} \\
\hline & & & & & \\
\hline ASD I & Morphine & $\begin{array}{r}3.7 \\
\pm 0.6\end{array}$ & $\begin{array}{l}35 \\
\pm 9\end{array}$ & $\begin{array}{l}\quad 6.5 \\
\pm 8\end{array}$ & $\begin{array}{l}64 \\
\pm 9\end{array}$ \\
\hline ASD II & Halothane & $\begin{array}{r}3.6 \\
\pm 0.5\end{array}$ & $\begin{array}{l}3: 3 \\
\pm 8\end{array}$ & $\pm 7^{48^{*}}$ & $\begin{array}{r}67 \\
\pm 9\end{array}$ \\
\hline TF 1 & Morphine & $\begin{aligned} & i .5 \dagger \\
\pm & 1.2\end{aligned}$ & $\begin{aligned} & 74 \dagger \\
\pm & 17\end{aligned}$ & $\begin{array}{r}5 ! ! \\
\pm 11\end{array}$ & $\begin{array}{l}86 i \dagger \\
\pm 7\end{array}$ \\
\hline TF II & Halothane & $\begin{aligned} & 5.7 \dagger \\
\pm & 1.0\end{aligned}$ & $\begin{aligned} & 78 \dagger \\
\pm & 19\end{aligned}$ & $\begin{array}{r}\text { in } \\
\pm 14\end{array}$ & $\begin{aligned} & 83 \dagger \\
& \pm 9\end{aligned}$ \\
\hline
\end{tabular}

${ }^{*} \mathrm{P}<0.05$, Students' t-test when compared to Group ASD 1 .

$\dagger P<0.0 \overline{5}$, Students' t-test when compared to Group ASD I or ASD II.

during these periods. Extracorporeal flow rates, times of bypass and total operative times were similar in groups TF I and TF II and in groups ASD I and ASD II (Table V).

Mean urine volumes and urine norepinephrine contents, concentrations and excretion rates are given in Tables II and III. Patients receiving morphine had urine outputs during all study periods that were similar to those undergoing the same operation with halothane. Urine flow rate was markedly higher $(P<0.01)$ in ASD I than in TF I patients both during induction and in all intra-operative periods. Urine norepinephrine excretion of the ASD patients receiving morphine was significantly increased $(\mathrm{P}<0.025)$ during induction (study period II) and during all subsequent study periods when compared to pre-operative controls. TF patients getting morphine had an increase in urine norepinephrine excretion beginning with bypass (period IV) and extending into the post-bypass and post-operative periods. Halothane recipients with $\mathrm{TF}$, on the other hand, had urine norepinephrine excretion rates which were significantly decreased $(\mathrm{P}<0.05)$ during induction and during 
all operative study periods when compared to pre-operative controls. Post-operatively, however, these patients had a significant elevation $(P<0.05)$ in urine norepinephrine excretion. ASD patients receiving halothane did not have urine norepinephrine excretion rates that were significantly different from pre-operative controls until the post-operative period, when they became significantly elevated $(\mathrm{P}<0.05)$.

Although morphine and halothane recipients having the same operative procedure had similar pre-operative urine norepinephrine excretion rates, patients anaesthetized with morphine excreted more norepinephrine during all subsequent study periods, frequently more than three times as much as their halothane counterparts.

\section{Discussion}

In two recent reports ${ }^{2,3}$ we have demonstrated that anaesthetic doses of morphine are associated with significant increases in urine norepinephrine excretion in patients during and after open-heart operations. Our findings have suggested that plasma norepinephrine levels are elevated by morphine and that the increase is greater and occurs sooner, that is during induction versus bypass, in patients with valvular heart disease than in patients with coronary artery disease. The reason for a different response in patients with these two types of disease states is not readily apparent but we suggested that a number of possible explanations could be advanced including differences in morphine blood levels, preoperative cardiac output, anaesthetic requirements and disease altered catecholamine responses to morphine. The present study was conducted to determine if children with congenital heart disease also respond to morphine by increasing urine norepinephrine excretion and, if so, whether those with cyanotic heart disease respond differently than those with non-cyanotic disease. It was also hoped that through analysis and comparison of these results with those previously obtained in patients with acquired heart disease, a better picture of the reasons for different norepinephrine responses to morphine might emerge.

Our findings in this investigation demonstrate that in children with Tetralogy of Fallot and atrial septal defect large doses of intravenous morphine are also associated with marked elevations in urine norepinephrine concentration but the responses are different in the two disease states. Patients with ASD had an immediate increase in norepinephrine excretion which persisted throughout the duration of the study and was similar to that of patients with mitral valve disease who were anaesthetized with morphine in our last study. Patients with TF, on the other hand, did not have an increase in urine norepinephrine until the bypass period, a response that was similar to our previous patients with coronary artery disease anaesthetized with morphine. Comparable patients with either ASD or TF who received halothane anaesthesia did not have significant elevations in urine norepinephrine until the post-operative period.

Comparison of ASD and TF children anaesthetized with morphine in this study with patients with coronary artery (CAD) and mitral valvular (MV) disease anaesthetized with morphine in our previous studies yields interesting similarities and differences. First, both MV and TF patients had similar and significantly higher 
pre-operative urine norepinephrine concentrations than patients with CAD and ASD. Second, MV and TF patients required lower amounts of morphine (1.5 and $2.8 \mathrm{mg} / \mathrm{kg}$ respectively) than CAD and ASD patients ( 3.5 and $3.4 \mathrm{mg} / \mathrm{kg}$ ). Third, patients with ASD and MV both experienced immediate and marked increases in urine norepinephrine excretion during induction of anaesthesia which persisted throughout the operation and early postoperative periods while patients with TF and CAD did not have significant elevations in urine norepinephrine excretion until bypass. Finally, ASD and MV patients had significantly higher norepinephrine excretion rates than their $\mathrm{TF}$ and $\mathrm{CAD}$ counterparts during all intra-operative study periods.

While the above suggests that increased circulating catecholamines may be the reason for the favourable response to morphine in patients with marginal cardiac reserve, it also raises the questions, "Why does morphine result in such diverse catecholamine responses in patients with different diseases" and "How dependent are these responses on pre-operative cardiac function and intra-operative cardiovascular dynamics"? The answers to these questions are not entirely clear but our findings together with previous animal and human studies allow some speculation as to the possible mechanisms involved.

Overy, Pfister and Chidsey ${ }^{5}$ have demonstrated that urinary norepinephrine is solely derived from circulating plasma norepinephrine. They have also found that clearance of plasma norepinephrine is not affected by changes in urine $\mathrm{pH}$ and flow and have demonstrated that urine norepinephrine excretion is a good indication of plasma norepinephrine concentration. Utilizing this technique, Chidsey, Braunwald and Morrow ${ }^{6}$ showed that patients in congestive heart failure, whether secondary to congenital or acquired heart disease, had markedly elevated urine norepinephrine excretions when compared to patients with similar cardiac lesions who were not in failure. They also found that urine epinephrine, in contrast to norepinephrine, was not significantly changed by the presence of congestive heart failure. Yoshida ${ }^{7}$ has described elevated levels of norepinephrine in patients in congestive heart failure secondary to mitral stenosis. Although this investigation and our previous studies were not designed to divide patients into those in and those not in congestive heart failure, it is interesting that none of our patients with CAD in the last study or with ASD in this one were taking diuretics or digitalis preparations or had any clinical evidence of heart failure. In contrast, all of our previous patients with MV had markedly elevated pre-operative pulmonary artery wedge and central venous pressures and were receiving digoxin and an array of diuretic preparations. Likewise, 12 of the 15 children with TF in this study had a tendency to accumulate œdema fluid and were receiving a diuretic and/or digoxin pre-operatively.

Increased pre-operative norepinephrine levels in $\mathrm{TF}$ patients could also be related to the prevention of excessive right-to-left shunting. It has been demonstrated that agents with $\beta$-adrenergic activity such as isoproterenol, or with vasodilatory effects such as amyl nitrite, will produce marked increases in intraventricular right-to-left shunting through the ventricular septal defect. ${ }^{8,9}$ It has been shown that this is due to increased contractility of the hypertrophied muscle in the right ventricular outflow tract resulting in right ventricular outflow obstruction and decreased systemic peripheral vascular resistance. A number of investigators have 
found that agents with pure alpha-adrenergic activity, such as angiotensin, or drugs which produce an increase in peripheral arterial resistance, such as propranalol, reverse the right-to-left shunt. ${ }^{8,10}$ It is conceivable that high endogenous plasma norepinephrine levels help prevent excessive right-to-left shunting in TF patients by maintaining an increased peripheral arterial resistance.

An explanation of the difference in urine norepinephrine excretion in response to induction of morphine anaesthesia in TF and ASD patients in this study may be related to morphine blood levels and urine output. Stanley and Isern-Amaral (unpublished data) have demonstrated that both morphine and its principal metabolite, morphine-3-monoglucuronide, are rapidly excreted as long as urine output is high. In a previous report ${ }^{3}$ we have also shown that in patients with similar urine output undergoing open-heart operations urinary norepinephrine excretion was inversely related to the total amount of morphine administered. Patients with CAD, aortic valve disease and $\mathrm{MV}$ received an average of $3.5 \pm 0.5,2.1 \pm 0.5$ and 1.5 $\pm 0.4 \mathrm{mg} / \mathrm{kg}$ of morphine respectively and excreted an average of $3.0,4.3$ and 4.8 $\mu \mathrm{g} /$ hour of norepinephrine. We suggested on the basis of these data that high morphine plasma concentrations may inhibit morphine stimulated endogenous norepinephrine secretion. This might occur during or immediately after induction with extremely large doses of morphine, such as $2 \mathrm{mg} / \mathrm{kg}$ body weight. While the above suggestion might appear to be in conflict with our findings in this study, since TF patients were given an average of $2.8 \pm 0.4 \mathrm{mg}$ of morphine and excreted only $2.8 \mu \mathrm{g} /$ hour of norepinephrine while ASD patients received $3.4 \pm 0.5 \mathrm{mg} / \mathrm{kg}$ of morphine and excreted an average of $5.2 \mu \mathrm{g} /$ hour of norepinephrine, the disparity may be explained by the significantly higher urine output of ASD patients than those with TF. Urine flow rate of ASD I patients was nearly twice that of TF I patients during induction and more than twice that of TF I patients during and after bypass. Markedly higher urine flow rates of ASD patients may have resulted in significantly lower plasma morphine levels and caused greater stimulation of endogenous norepinephrine release. Higher arterial blood pressures of group ASD I when compared to all other groups, especially during the pre-bypass and bypass periods, are compatible with less circulating morphine. Indeed, since pain is also a potent stimulus for catecholamine release, ${ }^{11}$ it is conceivable that greater intraoperative urine norepinephrine excretion in ASD I than TF I patients could have been due to inadequate analgesia or amnesia during the operation in the former. Anxiety, such as might occur from awareness during induction of anaesthesia or during the operation is another significant catecholamine stimulus. ${ }^{11}$ We have suggested that inadequate analgesia may have also been the mechanism of increased norepinephrine excretion during induction and the intra-operative periods in the patients with $\mathrm{MV}$ in our previous study. ${ }^{3}$ These patients received an average of only $1.5 \mathrm{mg} / \mathrm{kg}$ of morphine.

While it is generally recognized that patients with low cardiac output, such as those with MV, require lesser amounts of morphine for adequate anaesthesia than those with higher cardiac ouput, for instance patients with $\mathrm{CAD},{ }^{12}$ the minimal dose of morphine necessary for adequate anaesthesia has not been established for patients with acquired heart disease nor for that matter for those with TF or ASD. 
Morphine was given to both groups in this study until the patients were unconscious or until a maximum of $4 \mathrm{mg} / \mathrm{kg}$ had been administered. Although group ASD I received a mean of $0.6 \mathrm{mg} / \mathrm{kg}$ of morphine more than TF I it is possible that this was still not adequate to provide complete analgesia and amnesia, especially since the markedly greater urine output of ASD I patients was undoubtedly continually reducing morphine plasma levels at a much greater rate than they were being reduced in TF I patients. It is also possible that TF I patients received relatively greater amounts of morphine than required for adequate anaesthesia and amnesia and these doses were sufficient for "complete" anaesthesia early in the operative procedure. As morphine blood levels receded towards the end of the operation, less than adequate analgesia and amnesia resulted, which in turn caused increased norepinephrine release. We have suggested that the same mechanism may have been involved in CAD patients in our previous study who had a similar response to morphine as the TF I patients in this report. ${ }^{2}$ Careful discussions with all patients post-operatively revealed that no TF I, TF II or ASD II patients had recollection of any part of the operative procedure while two ASD I patients did have recall of some aspects of the procedure although they had felt no pain. It is possible others of this group were aware or had felt pain during the operation and repressed the memory post-operatively. A final piece of evidence in support of relatively lower morphine plasma leevls of group ASD I than TF I patients was the fact that four of ten of the former were able to sustain large enough tidal volumes $(>7 \mathrm{ml} / \mathrm{kg} /$ breath) and frequent enough respirations ( $>15$ breaths/minute) to be extubated during the afternoon of the day of the operation. None of TF I group patients were able to meet these respiratory criteria for extubation until the morning following the day of operation.

Our findings of increased excretion of norepinephrine during operation in patients anaesthetized with morphine but not in comparable patients anaesthetized with halothane suggest elevated plasma norepinephrine concentrations, but do not confirm that morphine stimulates the sympathetic nervous system. Increased renal excretion could be a manifestation of inhibition of norepinephrine re-uptake by nerve terminals, a change in route or rate of biodegradation, decreased cardiac, central nervous system or other organ stores of the amine, or increased release. In order to demonstrate the mechanism of increased norepinephrine excretion additional studies will be required in which urine and plasma norepinephrine concentrations and metabolites are measured simultaneously. Furthermore, for completeness, similar studies of plasma and urine epinephrine will also be necessary. Until recently this would have been impossible because of the large volume of blood necessary for each analysis and the relative insensitivity of spectrofluorometric techniques in quantitating plasma catecholamine changes. Roizen, Moss, Henry and Kopin ${ }^{13}$ seem to have overcome this obstacle by using a radiometric assay technique which requires only 0.6 to $1.0 \mathrm{ml}$ of blood and is sensitive to picogram amounts of norepinephrine. Perry, VanDyke and Theye ${ }^{14}$ also have reduced the amount of blood required for analysis with a modification of the trihydroxyindole method of catecholamine analysis introduced many years ago. To date, plasma catecholamine concentrations after morphine anaesthesia have not 
been measured using these sensitive techniques but obviously this will have to be done before the full effects of morphine on the sympathetic nervous system will be known.

\section{SUMMARY}

Urine excretion rates of norepinephrine were measured in 15 children with Tetralogy of Fallot and 25 with atrial septal secundum defects anaesthetized with halothane or morphine before, during and for two hours after surgical correction of their cardiac defects. All patients were paralyzed with d-tubocurarine, the tracheae were intubated and respiration was controlled. Urine was obtained for 90 minutes before induction, during induction, before, during and after bypass and postoperatively. Patients with TF had significantly higher pre-operative urine norepinephrine excretion rates than patients with ASD. In TF children anaesthetized with halothane norepinephrine excretion was significantly decreased during induction and during operation but increased post-operatively. Children with ASD and anaesthetized with halothane did not have urine norepinephrine excretion rates that were significantly different from pre-operative values until the postoperative period. ASD children anaesthetized with morphine had marked elevations in norepinephrine excretion during induction and all subsequent study periods. On the other hand, morphine anaesthetized TF children did not have a significant increase in urine norepinephrine excretion until bypass had been established. Increased norepinephrine excretion was maintained in these patients during all subsequent study periods. These data, when combined with our results in patients with acquired heart disease, demonstrate that disease can alter norepinephrine responses to morphine anaesthesia. In addition our results suggest that dosage of morphine and morphine blood levels might also modify norepinephrine excretion.

\section{RÉSUMÉ}

L'excrétion urinaire de Norépinéphrine a été mesurée avant, pendant et après réparation de la communication interauriculaire de l'ostium secundum et tétralogie de Fallot chez 40 enfants âgés de 6 à 11 ans, anesthésiés à la morphine ou à l'halothane. Vingt-cing de ces patients étaient porteurs de C.I.A. et 15 de T.F. Les premiers étaient légèrement plus lourds que les seconds $(37-29 \mathrm{~kg})$.

Tous les enfants ont été prémédiqués avec Atropine $(0.05 \mathrm{mg} / 10 \mathrm{~kg})$, Morphine $(1 \mathrm{mg} / 10 \mathrm{~kg}$ ) et pentobarbitone $(1 \mathrm{mg} / \mathrm{kg}), 90$ minutes avant l'intervention. Un cathéter vésical a été installé en même temps que l'enfant recevait sa prémédication et l'urine collectée jusqu'au début de l'induction.

Le maintien de l'anesthésie a été fait à la morphine chez 18 patients à la dose de $1-4 \mathrm{mg} / \mathrm{kg}$ à une vitesse d'injection IV de $5-15 \mathrm{mg} / \mathrm{min}$. et sous oxygène. Les autres enfants ont été anesthésiés par un mélange d'halothane et d'oxygène à une concentration 0.5 à 1.5 pour cent.

Les enfants ont été ventilés par un tube endotrachéal, à des volumes adéquats afin de garder une $\mathrm{PCO}_{2}$ entre 34 et $40 \mathrm{~mm} \mathrm{Hg}$ (torr). La curarisation a été obtenue par la DTC à $0.5-0.75 \mathrm{mg} / \mathrm{kg}$. 
Par la suite, la ventilation a été contrôlée durant les deux heures suivant l'intervention. Aucun agent inotropique n'a été utilisé durant les périodes étudiées.

Cette étude a été fragmentée en six périodes:

la lère étant la période pré-opératoire immédiate.

la 2ième allant du début de l'anesthésie au début de l'incision.

la 3ième allant de l'incision au début de la CEC.

la 4ième au cours de la CEC.

la 5ième de la fin de la CEC à la fin de lintervention.

la 6ième au cours des deux premières heures post-opératoires.

L'urine a été collectée pendant chacune de ces périodes et la concentration de Norépinéphrine dosée par la méthode fluorométrique de Viktora.

Le débit urinaire a été le même dans chaque groupe de patients, indépendamment de l'agent anesthésique utilisé. Chez les enfants porteurs de T.F., la concentration urinaire de Norépinéphrine dans la lère période ainsi que le taux d'excrétion ont été supérieurs $(36.6 \mu \mathrm{g} / 1$ et $2.9 \mu \mathrm{g} / \mathrm{h})$ à ceux des enfants porteurs de C.I.A. $(27 \mu \mathrm{g} / \mathrm{l}$ et $1.8 \mu \mathrm{g} / \mathrm{h})$.

Chez les enfants porteurs de C.I.A., anesthésiés à la morphine, on a trouvé une concentration urinaire élevée de Norépinéphrine pendant les 2ième et 3ième périodes par rapport à la période de contrôle; cette élévation n'a pas été notée chez les enfants anesthésiés à l'halothane.

Dans l'autre groupe d'enfants (T.F.) anesthésiés à la morphine, on a noté une augmentation significative de l'excrétion de Norépinéphrine pendant et après la CEC alors que ceux anesthésiés à l'halothane ont montré une diminution marquée de l'excrétion de Norépinéphrine.

Dans la période post-opératoire (chez tous les patients) on a noté une concentration élevée de Norépinéphrine.

Ces résultats suggèrent:

1. Que les patients T.F. ont des taux de sécrétions endogène de Norépinéphrine supérieurs aux patients porteurs de C.I.A.

2. Que l'anesthésie à la morphine produit une élévation de la concentration et de l'excrétion urinaires de Noréphinéphrine chez les enfants porteurs de cardiopathie congénitale.

3. Que le type de maladie modifie la réponse de la Norépinéphrine au cours de l'anesthésie à la morphine.

\section{REFERENCES}

1. Vasko, J.S., Henney, R.P., Oldham, H.N., Brawley, R.K., \& Morrow, A.G. Effects of morphine on ventricular function and myocardial contractile force. Am. J. Physiol. 210: 329 (1966).

2. Stanley, T.H., Isern-Amaral, J., \& Lathrop, G.D. The effects of morphine and halothane anesthesia on urine norepinephrine during and after coronary artery surgery. Canad. Anaesth. Soc. J. 22: 478 (1975).

3. Stanley, T.H., Isern-Amaral, J., \& Lathrop, G.D. Urine norepinephrine excretion in patients undergoing mitral or aortic valve replacement with morphine anesthesia. Anesth. \& Analg. 54:509 (1975). 
4. Viktora, J.K., Baukal, A., \& WolfF, F.W. New automated Huorometric methods for estimation of small amounts of adrenaline and nonadrenaline. Anal. Biochem. 23: 513 (1968).

5. Overy, H.R., Pfister, R., \& Chidsey, C.A. Studies on the renal excretion of norepinephrine. J. Clin. Invest. 46: 482 (1967).

6. Chidsey, C.A., Braumwald, E., \& Morrow, A.G. Catecholamine excretion and cardiac stores of norepinephrine in congestive heart failure. Am. J. Med. 39: 442 (1965).

7. Yoshida, Y. Studies on the pathologic physiology of pulmonary hypertension in mitral valve disease: $I$. The role of the sympathetic nervous system on the increment of pulmonary vascular resistance. Jap. Circ. J. 33: 359 (1969).

8. Shah, P.M. \& LANGFond, K. Circulatory effects of propranolol in children with Fallot's tetralogy. Am. J. Cardiol. 19: 653 (1967).

9. Cummings, G.R. Amyl nitrite induced changes in cardiac shunts. Brit. Heart J. 25: 525 (1963).

10. Cummings, G.R. Acute hemodynamic effects of angiotension II. Canad. M.A.J. 88: 827 (1963).

11. voN Eulen, U.S. Quantitation of stress by catecholamine analysis. Clin. Pharmacol. Ther. 5: 398 (1964).

12. Lowenstein, E. Morphine "anesthesia" - a perspective. Anesthesiology 35: 563 (1971).

13. Roizen, M.F., Moss, J., Henry, D.P., \& Kopin, I.J. Effects of halothane on plasma catecholamines. Anesthesiology 41: 432 (1974).

14. Perny, L.B., VanDyke, R.A., \& Theye, R.A. Sympathoadrenal and hemodynamic effects of isoflurane, halothane and cyclopropane. Anesthesiology 40:465 (1974). 